\title{
Le Mas-d'Azil
}

Grotte du Mas-d'Azil

Michel Menu

\section{(2) OpenEdition}

Édition électronique

URL : http://journals.openedition.org/adlfi/10614

ISSN : 2114-0502

Éditeur

Ministère de la culture

Référence électronique

Michel Menu, «Le Mas-d'Azil », ADLFl. Archéologie de la France - Informations [En ligne], Midi-Pyrénées, mis en ligne le 01 mars 1997, consulté le 20 avril 2019. URL : http://journals.openedition.org/ adlfi/10614

Ce document a été généré automatiquement le 20 avril 2019.

(c) Ministère de la Culture et de la Communication, CNRS 


\title{
Le Mas-d'Azil
}

\author{
Grotte du Mas-d'Azil
}

\section{Michel Menu}

\section{Identifiant de l'opération archéologique :}

Date de l'opération : 1990 - 1991 (RE)

Inventeur(s) : Menu Michel ; Walter P ; Vigears D ; Alteirac A

1 Une série de microprélèvements picturaux de pigment (huit) ont été faits par Michel Menu, Ph. Walter et D. Vigears (LRMF, Paris) accompagnés de A. Alteirac : un dans le réseau Xavier Leclerc (point rouge), quatre dans le réseau Breuil, secteur A (deux points rouges, deux sur le bisonnoir) et trois dans le réseau Breuil, secteur B (petit cheval rouge, cruciforme rouge et tête humaine noire).

2 Si les résultats de ces analyses ne sont pas encore connus, trois objets provenant de la galerie des Silex (collection Saint-Just Péquart) et datant du Magdalénien moyen indiquent l'emploi de l'hématite avec une charge de feldspath potassique (recette F de Niaux, cf. infra). Il s'agit d'une tête de cheval gravée, d'un contour découpé et d'une sagaie gravée. La même recette a pu également être reconnue pour la «tête de cheval décharnée» de la collection Piette, conservée au musée des Antiquités nationales. La gravure de vache précédée de son veau (Musée des Antiquités nationales) est quant à elle rehaussée de noir à base de manganèse avec traces de feldspath potassique. Ces résultats s'accordent avec l'interprétation chronologique de la recette $\mathrm{F}$, caractéristique du Magdalénien moyen ariégeois (Clottes et al., 1990). 
INDEX

Index chronologique : Paléolithique supérieur, Pléistocène supérieur operation Relevé d'art rupestre (RE)

Index géographique : Midi-Pyrénées, Ariège (09), Mas-d'Azil

peuple Magdalénien moyen 